\title{
RELIGION AND LIFE SATISFACTION DOWN UNDER
}

Michael A. Kortt. Southern Cross Business School, Southern Cross University, QLD, Australia

Brian Dollery. UNE Business School, University of New England, NSW, Australia

Bligh Grant. UNE Business School, University of New England, NSW, Australia

\section{Correspondence:}

Dr Michael A. Kortt

Senior Lecturer in Applied Economics

Southern Cross Business School

Southern Cross University

Gold Coast Campus Beachside

Locked Bag 4

Coolangatta QLD 4255

AUSTRALIA

p - 61-7-5589-3212

e - michael.kortt@scu.edu.au

25 January 2014 


\section{ABSTRACT}

We investigated the association between religious involvement and life satisfaction using panel data from the 2004, 2007, and 2010 waves of the Household, Income and Labour Dynamics in Australia (HILDA) survey. Our study provides strong evidence of an association between attendance at religious services and life satisfaction in the Australian social context. While social resources mediate this association, there appears to be a remaining direct influence of attendance at religious services on life satisfaction. To unravel this association, there is a need to disentangle and separately assess the influence that 'religious social resources' and 'secular social resources' may have on life satisfaction. 


\section{INTRODUCTION}

While the study of factors affecting subjective well-being has traditionally been central to the field of psychology (e.g., Argyle 2001; Diener et al. 1999), researchers from other disciplines such as economics and sociology are increasingly investigating a wide range of putative determinants of subjective well-being. Examples include the influence that money (e.g., Frijters et al. 2004) and religion (e.g., Lim and Putnam 2010) exert on subjective well-being. This burgeoning empirical literature has, in part, been fuelled by the development of reliable and valid measures of subjective well-being such as self-rating questions in surveys (Kahneman and Kreuger 2006) and the accessibility of happiness and life satisfaction data in large-scale surveys including the General Social Surveys, World Values Survey, and Eurobarometer Surveys (Frey and Stutzer 2002).

A wide range of factors can affect subjective well-being, including age, income, gender, education, genetics, number of children, marriage, employment, unemployment, self-reported health status, personality, social relationships, and major life events (Argyle 2001; Diener et al. 1999; Diener et al. 2009). In addition, a number of studies have also found that various aspects of religious behaviour such as involvement in religious services and strength of religious affiliation are positively associated with subjective well-being (e.g., Argyle 2001; Diener et al. 1999; Diener et al. 2009; Ellison 1991; Ellison et al. 2001; Ferris, 2002; Francis et al. 2003; Hadaway 1978; Hadaway and Roof 1978; Inglehart 2010; Maselko and Kubzansky 2006). However, not all research has found a link between religion and subjective well-being (e.g., Ciarrocchi and Deneke 2005; Lewis et al. 1997; Lewis 2002; Lewis et al. 2000). 
Moreover, there is considerable debate in the literature surrounding how religious behaviour actually influences subjective well-being. Some researchers emphasise the importance of social networks and social support (e.g., Krause 2008) while other researchers focus on the private and inner dimensions of religion (e.g., Greeley and Hout 2006). Two main theoretical explanations have been advanced in an effort to explain why religion may influence subjective well-being. The first explanation is that religious institutions, such as churches, synagogues, and mosques, enhance subjective well-being by providing individuals with access to social networks and support structures (e.g., Ellison 1995; Ellison and George 1994; Krause 2008). The second explanation is that the private and inner dimensions of religion (such as the 'belief in a divine other' and the 'belief in an afterlife') may be positively associated with subjective well-being (Ellison 1991; Greeley and Hout 2006; Pollner 1989). While it remains far from clear which dimension of religion plays a more significant role in influencing life satisfaction (Lim and Putnam, 2010), the present study examines the importance of social resources in context of contemporary Australian society.

In the empirical literature, many studies rely on cross-sectional data and are therefore unable to control for unobserved individual heterogeneity, which may account for the association between religion and life satisfaction (Lim and Putnam 2010). In order to investigate this question further and account for unobserved individual heterogeneity, there is a need for additional research to examine these relationships in more detail using panel datasets. 
Against this background, we contribute to the literature by using data derived from the Household, Income and Labour Dynamics in Australia (HILDA) survey - a large and representative panel survey of the Australian population - to explicitly examine the association between religious behaviour and life satisfaction and what role, if any, social resources may play in mediating this relationship.

\section{THEORETICAL AND EMPIRICAL CONTEXT}

\subsection{Conceptual matters}

Individuals assess their level of subjective well-being with respect to their own circumstances and comparisons to other individuals, past experiences, and future expectations (Frey and Stutzer 2002). Subjective well-being itself consists of an 'affective' domain and a ‘cognitive’ domain (Diener et al. 1999). The 'affective' domain includes emotions and moods that reflect an individual's immediate reaction to and evaluation of events occurring in their life. The 'cognitive' domain refers to the 'intellectual' dimension of subjective well-being and is usually assessed with measures of life satisfaction (Diener et al. 1999; Frey and Stutzer 2002). Lucas, Diener and Suh (1996) have demonstrated that unpleasant affect, pleasant affect, and life satisfaction are, in fact, separable constructs. Against this conceptual background, it is important to stress that the focus of the present study is to examine the association between religion and life satisfaction (i.e., the 'intellectual' dimension of subjective well-being) in contemporary Australian society. 


\subsection{The influence of religion on subjective well-being}

One of the most comprehensive reviews of the association between religious behaviour and life satisfaction was conducted by Koenig, McCullough and Larson (2001). The authors reviewed 100 studies that examined the statistical association between religion and life satisfaction and found that: (i) 79 studies reported a positive association; (ii) 13 studies found no association; (iii) seven studies were inconclusive; and (iv) one study found a negative association. The principal conclusions drawn from this body of research are that: (a) religious belief is predictive of life satisfaction (by fostering a sense of purpose in life); and (b) attendance at religious services is also predictive of life satisfaction (by fostering a sense of communal belonging).

It is worth noting that in those studies that observed a positive association between religious behaviour and life satisfaction, the magnitude of this relationship is considerable (Inglehart 2010). Based on a meta-review, Witter et al. (1985) estimated that religious participation accounted for between 2 and 6 per cent of the observed variation in subjective well-being. In a similar vein, Ellison (1991) has reported that religious variables accounted for between 5 and 7 per cent of the variation in life satisfaction but only between 2 and 3 per cent of this variation can be attributed to the 'affective' dimension of subjective well-being. This suggests that the benefits conferred by religion are largely 'cognitive' and provide individuals with an interpretative framework to help them make sense of life (Diener et al. 1999).

In many studies, attendance at religious services is consistently reported as being a strong predictor of subjective well-being (e.g., Argyle 2001; Diener et al. 1999; 
Ellison et al. 2001; Ferris 2002; Francis et al. 2003), although other studies have found that the private and inner dimensions of religion (such as a 'closeness to God') are also associated with subjective well-being (e.g., Argyle 2001; Ellison 1991; Greeley and Hout 2006; Pollner 1989).

However, most studies that have investigated the relationship between religion and subjective well-being have employed cross-sectional datasets (Ellison and Levin 1998; Lim and Putnam 2010) and are therefore unable to control for unobserved individual-level heterogeneity. Nevertheless, there are several panel studies that have been able to provide a more robust investigation into the causal effects of various religious aspects on subjective well-being (Krause 2006; Krause and Ellison 2009; Levin and Taylor 1998; Lim and Putnam 2010).

Using a nationally representative panel study of African Americans, Levin and Taylor (1998) failed to find a longitudinal effect of public and private religious involvement (such as religious attendance and prayer) on subjective well-being. In contrast, Krause (2006: 298), using data drawn from a national longitudinal survey of older White and African Americans, found that "religious doubt is associated with a diminished sense of well-being over time” and, more recently, Krause and Ellison (2009: 293) also found that "suppressing religious doubt is associated with less favourable health ratings over time”.

Lim and Putnam (2010) conducted one of the most comprehensive panel studies to examine the effect of religious involvement on life satisfaction. Using data collected in 2006 and 2007 as part of the Faith Matters Study, which was designed to 
investigate the link between religion and social capital, Lim and Putnam (2010) provide strong empirical evidence that most of the influence on life satisfaction is mediated by friendship networks that worshippers build in their congregations. With the added advantage of being able to separate the effect of 'religious social resources' and 'secular social resources', they also note that this relationship is conditional upon the presence of a "strong religious identity” (Lim and Putnam 2010: 923). Put differently, the effect of congregational friendships varies according to the level of importance that individuals attach to their religious identity. Finally, the authors note that there was limited empirical evidence to support the proposition that private and subjective religious dimensions directly influenced life satisfaction, after controlling for service attendance and congregational friendships.

\subsection{Why is religion important?}

In studying the relationship between religion and subjective well-being, the following question arises: why should individuals involved in religious activities - particularly attendance at religious services - report higher levels of subjective well-being? One theoretical explanation, which has its origins in the work by Durkheim (1951), is that religious institutions provide like-minded individuals with: (i) access to social networks and support structures; and (ii) a meeting place to engage in regular social interactions (Argyle 2001; Ellison 1991; George et al. 2002; Krause 2008).

Moreover, individuals who are members of religious institutions are more likely to benefit from larger social networks, especially in times of need (Ellison 1991). However, while this theoretical explanation is inherently appealing, there is limited empirical evidence to directly support it (Lim and Putnam 2010). For example, 
Ellison et al. (1989) and Greeley and Hout (2006) have found that the relationship between religion and subjective well-being remained statistically significant despite efforts to control for social resources. Furthermore, Lim and Putnam (2010) also note that many of these studies do not draw the distinction between 'religious social resources' and 'secular social resources' and they have subsequently put forth a case that this distinction should be made in order to establish whether religious social resources have a direct influence on subjective well-being.

A second theoretical explanation centres on how the private and inner dimensions of religion enhance individual subjective well-being (Argyle 2001; Ellison 1991; Ellison et al. 1989; Greeley and Hout 2006). Pollner (1989) argues that individuals may build relationships with 'divine others' in a bid to secure spiritual guidance and comfort. Furthermore, interactions with these 'divine others' by way of prayer and meditation may also help to bolster an individual’s self-efficacy and self-esteem (Ellison 1991). Pollner (1989: 93) further suggests that a belief in a 'divine other' may also enhance subjective well-being by contributing to "perceptions of orderliness and predictability of events” and can even provide a framework for “explaining problematic occurrences”.

In exploring these relationships, Ellison (1991) found that the inclusion of private and subjective religious dimensions reduced the association of service attendance on life satisfaction to a statistically insignificant level. On the other hand, Pollner (1989) found that attendance at religious services was still significantly associated with life satisfaction even after controlling for these dimensions. Even if these variables (i.e., interactions with 'divine others') are considered to be attenuating factors, there may 
still be a need to explain any "remaining direct influence of attendance" on life satisfaction (Lim and Putnam 2010: 917).

\subsection{Religion in the Australian context}

Given that the analysis in this article takes place within the context of contemporary Australian society, it is worth reviewing the key theoretical and empirical literature that exists within this landscape. Perhaps the most significant contributions to the Australian literature have been made by Kaldor et al. (2010) and Kaldor et al. (2012). Between 2001 and 2010, a pioneering research project was initiated and conducted to: (i) investigate how people make sense of life in contemporary Australian society; and

(ii) determine how these different approaches to making sense of life influence individual and community well-being (Kaldor et al. 2012). In order to realise these objectives, the 2002 Wellbeing and Security Survey was specifically designed and administered to collect comprehensive information on a range of constructs including social capital, personal values, and life satisfaction, as well as information on religious beliefs and practices (Kaldor et al. 2010).

With regard to how Australians make sense of life and gauge its ultimate importance, Kaldor et al. (2010: 5) identified a range of approaches including: (i) religious approaches that draw "predominantly on a specific religious tradition" in order to explore and "make sense of life through that tradition"; (ii) alternative spiritual approaches that focus on the "fashioning of a personal spirituality that may draw selectively from various spiritual perspectives and practices”; and (iii) predominantly secular approaches that involve "making sense of life with little or no reference to religious or spiritual perspectives”. A key finding from this research is that $30 \%$ of 
Australians are "influenced by religious thinking about how to make sense of life" (Kaldor et al. 2012: 94).

However, a particularly important question is whether there are any links between how Australians make sense of life and individual and community well-being (Kaldor et al. 2012). From a theoretical perspective, Kaldor et al. (2012: 99/104) propose that how one makes "sense of life" influences one’s attitudes towards, inter alia, a "sense of purpose of life”, which, in turn, influences individual and community well-being. In this context individual well-being refers to living standards, health status, mental well-being, life satisfaction, coping with adverse life experiences, safety and security and interpersonal well-being, while community well-being refers to "trust in others", “core values”, and “contributing to others” (Kaldor et al. 2012: 99). In essence, the principal finding was that "how people make sense of life can affect their personal well-being and the wider well-being of the communities in which they live” (Kaldor et al. 2012: 104). More specifically, these results suggest that those individuals who were classified as ‘reflectively Christian’ (i.e., it is acceptable to questions one’s belief) had, on average, higher levels of well-being, volunteering, and levels of trust and that "lower levels of this group in society may have a negative impact on the well-being and resilience of the community at large” (Kaldor et al. 2012: 105).

\subsection{Research questions}

Against this background, we contribute to the literature by using data drawn from the Household, Income and Labour Dynamics in Australia (HILDA) survey, which contains information on religion and life satisfaction as well as comprehensive data on demographic, social, and economic characteristics of its participants. The HILDA 
survey provides us with a unique opportunity to address the following research questions for Australia:

a) Is frequency of attendance at religious services positively related to life satisfaction?

b) Does frequency of attendance at religious services have an independent influence on life satisfaction after controlling for social resources (i.e., the number of friends and level of social interaction)?

By addressing these research questions, we are able to empirically test whether frequency of attendance at religious services is positively associated with life satisfaction and what role social resources may play in mediating this relationship. Our study also contributes to the literature in the following ways: (i) we provide - to the best of our knowledge - the first results for Australia; and (ii) we exploit the panel nature of the HILDA survey to more effectively account for unobserved individuallevel heterogeneity.

However, while the research questions posed in this study investigate a relationship that runs from religion to social resources to life satisfaction it is important to keep in mind that many of these relations have been shown to be bi-directional. For example, a number of studies have found that positive well-being precedes increased social interactions and positive social outcomes (see, e.g., Adams 1988; Lyubomirsky et al. 2005a; Lyubomirsky et al. 2005b). 


\section{DATA AND METHODS}

The data used in this study were derived from the Household, Income and Labour Dynamics in Australia (HILDA) survey, which is Australia’s first nationally representative household panel survey (Wooden and Watson 2007). The HILDA survey commenced in 2001 (Wave 1) and was based on a large national probability sample of Australian households with a major focus on families, income, employment, and subjective well-being. Wave 1 consisted of 7,696 households and 13,696 individuals. Households were selected using a multi-stage sampling strategy and a 66 per cent response rate was obtained. Within each household, information was collected from each household member aged 15 and over, using face-to-face and self-assessed questionnaires. A 92 per cent household response rate was obtained in Wave 1 and, in each subsequent wave, between 87 and 95 per cent of survey participants were retained. For an excellent discussion on the survey design, sampling methods, and content, see Wooden and Watson (2007).

In this study, we focus on participants aged 18 years and over from the 2004, 2007 and 2010 waves of the HILDA survey, which are the only waves (to date) to have collected information on religion (i.e., affiliation and attendance). The major advantage of using the HILDA survey is that it is one of the largest surveys in Australia to collect data on religiosity and life satisfaction as well as detailed sociodemographic and economic information on its participants. Our cross-sectional regression analysis is based on an analytic sample of 28,962 individuals and our panel analysis is based on a balanced analytic sample of 5,892 individuals (with an average of 3 wave observations). 


\section{Life satisfaction measure}

In the HILDA survey, life satisfaction is assessed in annual face-to-face interviews using the following question: “All things considered, how satisfied are you with your life?” Respondents are told to: "Pick a number between 0 and 10 to indicate how satisfied you are" and that "the more satisfied you are, the higher the number you should pick”. The responses ranged from 0 (totally dissatisfied) to 10 (totally satisfied). This measure of subjective well-being has been shown to be closely related to other potentially more objective measures of happiness (Frey and Stutzer 2002). Table 1 shows the pooled distribution of responses to the life satisfaction question, with over two-thirds of respondents reporting a life satisfaction score of 8 or higher.

\section{Religiosity measures}

Religiosity was identified using two survey questions that asked respondents about: (i) their religious affiliation; and (ii) their frequency of attendance at religious services.

Religious affiliation was identified by a set of dummy variables identifying Catholic (23\%), Anglican (20\%), Other Christian (23\%) and Non-Christian (3\%) affiliations. Participants who reported no religious affiliation (30\%) were selected as the excluded reference group in the subsequent regression analysis. The Australian Bureau of Statistics (2011) Australian Standard Classification of Religious Groups was used to categorise religious affiliation. 
Religious participation was assessed by the following question: "How often do you attend religious services? Please do not include ceremonies like weddings or funerals." Frequency of attendance at religious services was coded as: $1=$ never, $2=$ less than once a year, 3 = about once a year, $4=$ several times a year, $5=$ about once a month, $6=2$ or 3 times a month, $7=$ about once a week, $8=$ several times a week, and 9 = every day

\section{Social resources measures}

Social resources and networks were measured using two variables available to us in the HILDA survey. Our first social resource measure was assessed by the following question: "I seem to have a lot of friends". Responses ranged from 1 ("strongly disagree”) to 7 (“strongly agree”). Our second social resource measure was assessed by the following question: "How often do you get together socially with friends/relatives not living with you?” Responses to this question ranged from 1 (“less often than once every three months") to 7 ("every day”).

\section{Control variables}

Guided by the previous literature (Argyle 2001; Diener et al. 2009; Diener et al. 1999), we included the following common predictors of life satisfaction: age in years, sex $\left(1=\right.$ female; 0 = male), years of education, ${ }^{1}$ income (financial year gross wages and salary scaled to $\$ 10,000)$, marital status ( 1 = married; 0 = not married), number of children, self-reported health status (a five point scale ranging from $1=$ poor to $5=$

\footnotetext{
${ }^{1}$ Years of education is coded as the highest year of completed schooling if the respondent has no postschool qualifications (i.e., less than 8 years is coded as 8 years). Post-school qualifications are coded into years as follows: masters $/$ doctorate $=$ 'top coded' at 17 years; graduate diploma/certificate $=16$ years; bachelor degree $=15$ years; diploma $=12$ years; and certificate $=12$ years.
} 
excellent), unemployment status ( $1=$ unemployed; $0=$ employed $)$, and the number of major negative life events (ranging from 0 to 7) in the previous 12 months.

However, there is some discussion in the literature over whether one should include marital status as a control variable in a context such as this. The central question is: if marital status is considered to be part of one’s social resources should it be included as a control variable? This is particularly important in the current context as we are principally interested in determining whether our measure of social resources mediates the relationship between attendance at religious services and life satisfaction. While similar studies typically include marital status as a covariate (see, e.g., Lim and Putnam 2010) it is important to note that other studies have shown that 'romantic relationships' - as opposed to friendships - have a greater impact on subjective wellbeing (see, e.g., Demir 2010). To investigate the possible role that marital status may play, we estimated our most extensive regression specification (Equation 1 below) with and without marital status. Our results - available upon request - indicate that the inclusion of marital status makes very little difference to our results (i.e., our estimated coefficients for 'attendance at religious services' and 'social resources' $d o$ not noticeably change when marital status is introduced as a control variable). Thus, we opt to retain marital status as a control variable, which, in turn, also facilitates the comparison of our findings with those from similar studies (e.g., Lim and Putnam 2010).

Our composite measure of negative life events was constructed by identifying whether respondents reported experiencing either one or more of the following major life events: separation, major illness, major illness of family member, death of 
spouse/child, death of family member, death of close friend, victim of physical violence, victim of property crime, detention in jail, detention of family member in jail, or major worsening of finances. The descriptive statistics for all variables are presented in Table 2.

\section{Empirical strategy}

To investigate the relationship between religion and life satisfaction we estimated a series of regression models, with life satisfaction as the dependent variable. In our first specification we only included indicator variables for religious affiliation to explore whether different religious traditions exert differential impacts on life satisfaction. In our second specification we introduced our extensive range of control variables to determine whether these factors account for the relationship between religious affiliation and life satisfaction. In our third specification, we introduced frequency of attendance at religious services to ascertain whether frequency of attendance is positively related to life satisfaction. In our fourth specification, we introduced our measures of social resources to investigate whether the relationship between 'attendance' and life satisfaction is operating via these social networks. Thus, our most extensive specification is:

$$
\mathrm{LS}_{\mathrm{it}}=\alpha+\beta_{1} \mathbf{X}_{\mathrm{it}}+\beta_{2} \mathbf{R}_{\mathrm{it}}+\beta_{3} \mathrm{~S}_{\mathrm{it}}+\mathrm{a}_{\mathrm{i}}+\mu_{\mathrm{it}}
$$

In Equation (1), LS is the respondent's life satisfaction score, $\mathbf{X}$ is a vector of exogenous control variables (i.e., age in years, sex, years of education, income, marital status, number of children, self-reported health status, unemployment status, and the number of major negative life events in the previous 12 months), $\mathbf{R}$ is a vector 
of religious variables (i.e., religious affiliation and frequency of attendance at religious services), $\mathbf{S}$ is a vector of social resources (i.e., number of friends and frequency of social contact), $a_{i}$ is the 'fixed-effect' over time, and $\mu_{i}$ is an i.i.d. error term.

In modelling life satisfaction, several studies have established that estimates of the determinants of life satisfaction remain virtually unchanged whether one models life satisfaction as either an ordinal (e.g., using an ordered logistic or probit model) or cardinal (e.g., using an ordinary least squares model) variable (Ferrer-i-Carbonell and Frijters 2004). Thus, for ease of estimation and interpretability of the regression coefficients we treat life satisfaction as a cardinal variable.

We initially estimated Equation 1 using ordinary least squares (OLS). Since we observe the same individuals in 2004, 2007, and 2010, our standard errors are clustered at the person level to account for within-person serial correlation. We then exploited the panel nature of our dataset and controlled for unobserved individuallevel heterogeneity and estimated the relationship between religion and life satisfaction using a fixed-effects regression model. The major advantage of the fixedeffects regression approach is that it controls for time-invariant factors $\left(a_{i}\right.$ in Equation 1) such as sex, race, cognitive ability, and personality, which may affect the dependent variable and, in turn, reduces the impact associated with omitted variable bias. 


\section{RESULTS}

In Table 3 we report our OLS regression results, which are based on a sample of 28,962 individuals. In Model I we only included our indicator variables for religious affiliation. In terms of life satisfaction, the estimated coefficients indicated that there is a statistically significant difference between each religious category (except the 'Non-Christian’ category) and the excluded reference group ('no religion'). For example, Model I indicated that Anglicans had, on average, a 0.2 higher life satisfaction score compared to individuals reporting no religious affiliation.

In Model II we introduced our control variables. While the inclusion of these control variables substantially attenuated the difference between 'no religion' and the 'Catholic', ‘Anglican’ and ‘Other Christian’ affiliations, the ‘Anglican’ affiliation is the only religious category to remain statistically significant. Inclusion of the control variables also explains 15 per cent of the total variation in life satisfaction. All control variables are statistically significant at the 1 per cent level. Age $(\beta=0.013)$ and the indicator variables representing married $(\beta=0.255)$ and female respondents ( $\beta=0.088$ ) showed a positive effect on life satisfaction. Self-reported health status ( $\beta$ $=0.547$ ) was also positively and strongly related to life satisfaction. The indicator variable representing the unemployed $(\beta=-0.315)$ showed a relatively strong negative association with life satisfaction. Somewhat surprisingly, education $(\beta=-0.056)$, income ( $\beta=-0.010)$, and children $(\beta=-0.025)$ were negatively associated with life satisfaction. Finally, a negative association on life satisfaction was also observed for those respondents who reported experiencing a greater number of traumatic events in the previous 12 months $(\beta=-0.112)$. 
In Model III we incorporated our measure of frequency of attendance at religious services. The inclusion of our attendance variable was statistically significant at the 1 per cent level $(\beta=0.028)$. Comparing Models II and III, the inclusion of the 'attendance' variable only marginally improves our $\mathrm{R}^{2}$ value and there is virtually no change in the estimated coefficients on the control variables.

However, while inclusion of 'attendance’ in Model III only marginally improves our $\mathrm{R}^{2}$ value it does, in fact, further attenuate the impact of our 'Catholic', 'Anglican', and 'Other Christian’ variables. Somewhat surprisingly, however, our indicator variables for the 'Non-Christian’ category (e.g., Buddhists, Muslims, Hindus, and Jews) is negative and statistically significant in Model III, although this finding needs to be treated with caution as this group only comprises 3 per cent of our sample. It is entirely plausible that if the 'Non-Christian' category had been oversampled (and thus permitted a finer classification of the 'Non-Christian' category) then the current result may not hold.

Overall, the results in Model III suggest that frequency of attendance at Anglican religious services may account for the observed differences between subjective life satisfaction between Anglicans and non-religious individuals. Thus, in terms of life satisfaction, it appears that involvement in the religious community is what counts and not whether that religious community is Anglican. 
In Model IV we included our social resources variables. The coefficient on our 'friends' variable is positive and statistically significant $(\beta=0.154 ; p<0.01)$. Our 'social contact' variable is also positive and statistically significant $(\beta=0.067 ; p<$ 0.01). Overall, these results suggest that there is a strong relationship between our measures of social resources and life satisfaction. While the inclusion of our social resources measures mediates our 'attendance’ variable it remained statistically significant $(\beta=0.013 ; p<0.01)$. We also conducted Sobel mediation tests (Sobel, 1982) and found statistically significant indirect effects of attendance on life satisfaction through both our 'friends' $(\mathrm{Z}=16.16 ; p<0.01)$ and 'social contact' $(\mathrm{Z}=$ 11.00; $p<0.01)$ variables.

Moreover, the inclusion of our social resources measures appreciably increased the $\mathrm{R}^{2}$ value from 15.5 per cent to 19.5 per cent. These results, which are consistent with findings from the U.S. (e.g., Ellison et al. 1989; Greeley and Hout 2006) suggest that the positive impact of 'attendance' on life satisfaction is being exerted partly through our measure of social resources. In other words, the relationship between religious involvement (i.e., frequency of attendance at religious services) and life satisfaction remains robust even after controlling for social resources (i.e., the number of friends and frequency of social contact).

While the results of our cross-sectional analysis provides evidence that frequency of attendance at religious services bolsters life satisfaction, we cannot dismiss the possibility that unobserved individual-level differences between survey participants are responsible for the results reported in Table 3. Thus, in order to examine this 
issue further, we turn to our fixed-effects (FE) regression analysis in Table 4, which was derived from a balanced panel of 17,676 wave observations (i.e., the same 5,892 individuals in 2004, 2007, and 2010). In our FE regression analysis, we estimated the relationship between life satisfaction and religious affiliation, ‘attendance’ and social resources with and without our control variables (i.e., Models I and II in Table 4). In Model I, we observed a statistically significant positive relationship between 'attendance' and life satisfaction $(\beta=0.034 ; p<0.01)$. Moreover, we still observed a relatively strong positive relationship between 'friends' $(\beta=0.072 ; p<0.01)$ and 'social contact' $(\beta=0.036 ; p<0.01)$. Turning to Model II, the inclusion of the additional control variables had very little impact on our estimated coefficients.

While our FE panel analysis controls for unobservable individual heterogeneity and arguably provides a more stringent empirical assessment of the relationship between religious participation and life satisfaction, it is possible that a random effects (RE) specification may be more appropriate. In the RE model, it is assumed that the unobserved effect, $a_{i}$, in Equation (1) is uncorrelated with each independent variable across each time period. To explore this issue further, the results from the RE regression specification are also reported in Table 4 (i.e., Models III and IV). In essence, these results are consistent with the findings from our FE regression analysis (i.e., there is a statistically significant positive association between 'attendance', 'friends', 'social contact', and life satisfaction).

Although a theoretical argument can be mounted that a FE specification is preferred to a RE specification on the grounds that unobserved variables such as personality traits are likely to be highly correlated with our independent variables, we conducted a 
Hausman specification test to empirically determine whether our FE specification (i.e., Models I and II in Table 4) is preferred to our RE specification (i.e., Models III and IV in Table 4). In this test, the null hypothesis $\left(\mathrm{H}_{0}\right)$ is that the RE model is the appropriate specification versus the alternative hypothesis $\left(\mathrm{H}_{1}\right)$ that the FE model is the appropriate specification. Based on the results from the Hausman tests we rejected the null hypothesis and concluded that the FE model is the appropriate specification.

\section{DISCUSSION}

In this paper we examined the association between religion and life satisfaction in Australia. Drawing on data from the HILDA survey, we were able to contribute to the literature by examining whether frequency of attendance at religious services: (i) is positively related to life satisfaction; and (ii) has an independent influence on life satisfaction after controlling for social resources.

With respect to our cross-sectional analysis, a number of findings are worth noting. First, our results confirm the importance of a core set of control variables in estimating individual life satisfaction, which are broadly consistent with previous studies (Argyle 2001; Diener et al. 1999; Diener et al. 2009). Indeed, our block of control variables accounts for most of the explanatory power in our series of regression models and remains statistically significant across all four models. Regarding our set of control variables, self-reported health status and marital status have the most substantial positive influence on life satisfaction while unemployment status and the number of negative life events have the most substantial negative influence on life satisfaction. 
Second, the inclusion of our 'attendance' variable in Model III (Table 3) indicates that there is a statistically significant positive association between frequency of attendance at religious services and life satisfaction. Moreover, while the introduction of our social resources variables in Model IV (Table 3) mediates our 'attendance' variable, it still remains statistically significant. This result, which is consistent with findings from the U.S. (e.g., Ellison et al. 1989; Greeley and Hout 2006), suggests that frequency of attendance at religious services exerts an independent influence on life satisfaction even after controlling for social resources.

We also took advantage of the panel nature of the HILDA dataset to further examine the relationship between religion and life satisfaction using a balanced panel of respondents. In line with our cross-sectional analysis, our panel data revealed that frequency of attendance at religious services exerts a strong independent influence on life satisfaction even after controlling for social resources (a finding that is robust to competing panel specifications). In other words, our results provide evidence that religious participation has both a direct and indirect effect (via both social resource variables) on life satisfaction.

However, a number of scholars have proposed that 'religious social resources' confer a number of benefits by providing members with a greater sense of comfort, identity, and belonging (e.g., Ellison and George 1994; Haslam et al. 2009; Krause and Wulff 2005; Krause 2008). To further explore this possibility, we believe that a fruitful avenue of research in the Australian context would be for future panel studies to collect data which draw a clear distinction between 'religious social resources' and 
'secular social resources'. This, in turn, would allow researchers to subsequently unravel and determine whether 'religious social resources' have a direct influence on life satisfaction in contemporary Australian society.

While our panel analysis provides strong evidence of a relationship between religious attendance and life satisfaction, it is conceivable that other changes in the lives of survey participants may have led to the corresponding changes in attendance at religious services and life satisfaction. However, individuals may self-select into religion based on expected benefits associated with religious participation and it is possible that "the benefit of religion may thus be limited to those who decide to become religious"; conversely, individuals may decide to leave a religion "because they fail to find happiness in it” and thus individuals who leave religion may increase in life satisfaction (Lim and Putnam 2010: 925). Although our panel analysis estimates the mean effect on those individuals who experienced religious change, it does not address the potential influence of these religious ‘joining' and 'leaving' effects. We concur with Lim and Putnam (2010) that future research is needed to resolve these issues and, as a result, our findings should be viewed as being indicative rather than authoritative.

More generally, the following caveats need to be taken into account when interpreting our findings. First, our study is principally confined to Australian Christians. This is not a trivial point as subjective well-being has been shown to vary with respect to culture and nationality. For example, Confucian cultures like China regard the optimal level of life satisfaction as one of neutrality and there is a higher acceptance of negative feelings and lower acceptance of positive feelings (Diener et al. 2009). 
With respect to nationality, Argyle (1999) has reported that the link between religion and happiness is stronger for Americans compared to Europeans and, more recently, Levin (2012) has demonstrated that the influence of religion on life satisfaction (and happiness) differs between Israeli and diaspora Jews.

Second, finding an association between religiosity and subjective well-being may depend on how subjective well-being is measured. For example, in a review by Lewis and Cruise (2006) it was reported that research with the Oxford Happiness Inventory consistently found that religion was associated with happiness while research using the Depression-Happiness Scale consistently found the converse.

Third, our social resources measures unfortunately do not capture the quality of friendships, which is a distinct and important source of subjective well-being (Diener et al. 2009; Demir et al. 2013). Research has demonstrated that both the size of one's friendship network (Burt 1987; Lee and Ishii-Kuntz 1987; Requena 1995) and quality of friendships (Demir et al. 2013) are correlated with subjective well-being. The strength of the association between the quantity of friends and subjective well-being is relatively small, with correlations usually in the range of 0.1 to 0.2 (Demir et al. 2013; Pinquart and Sörensen 2000). In comparison, the strength of the association between the quality of friendships and subjective well-being is typically larger with correlations in the range of 0.2 to 0.5 (Demir et al. 2013). Against this background, consideration should be given to collecting data on friendship quality in future waves of the HILDA survey. 
Finally, assessing life satisfaction with a single question is limiting. In the current context, it provides no way to assess life satisfaction in different circumstances or dimensions of our lives. In other words, it is entirely plausible that religion is connected to some but not all dimensions of our lives in terms of subjective wellbeing. In an effort to explore 'another dimension of well-being' we re-ran our analysis using self-reported health status (as measured through the SF-36 general health survey). Our results (available upon request) were mixed. Our cross-sectional analysis indicates that while attendance at religious services was associated with selfreported health, this association was attenuated when our measures of social resources were introduced. On the other hand, our panel analysis revealed that there was no association between attendance at religious services and self-reported health status. This analysis provides at least some preliminary evidence that attendance at religious services - in the Australian social milieu - is connected to some but not all aspects of our lives in terms of subjective well-being.

\section{CONCLUSION}

We examined the relationship between frequency of attendance at religious services and life satisfaction using panel data from the 2004, 2007, and 2010 waves of the HILDA survey. Our study provides strong evidence of an association between frequency of attendance at religious services and life satisfaction in the Australian social context. While social resources mediate this association, there appears to be a remaining direct influence of attendance at religious services on life satisfaction. To unravel this relationship, we believe that there is a need to disentangle and separately assess what influence ‘religious social resources’ and ‘secular social resources’ may have on life satisfaction in contemporary Australian society. 


\section{Acknowledgments}

This paper uses unit record data from the Household, Income and Labour Dynamics in Australia (HILDA) Survey. The HILDA Project was initiated and is funded by the Australian Government Department of Social Services (DSS) and is managed by the Melbourne Institute of Applied Economic and Social Research (Melbourne Institute). The findings and views reported in this paper, however, are those of the author and should not be attributed to either DSS or the Melbourne Institute.

The authors would also like to thank the editors and three anonymous referees for very helpful comments on an earlier version of this paper. 


\section{REFERENCES}

Adams, R. G. (1988). Which comes first: Poor psychological well-being or decreased friendship activity? Activities, Adaptation \& Aging, 12, 27-41.

Argyle, M. (1999). Causes and correlates of happiness. In D. Kahneman, E. Diener \& N. Schwarz (Eds.), Well-being: The foundations of hedonic psychology. New York: Russell Sage Foundation.

Argyle, M. (2001). The psychology of happiness. London: Routledge.

Australian Bureau of Statistics (2011). Australian standard classification of religious groups (1266.0). Canberra: ABS.

Burt, R. S. (1987). A note on strangers, friends and happiness. Social Networks, 9, 311-331.

Ciarrocchi, J. W., \& Deneke, E. (2004). Happiness and the varieties of religious experience: Religious support, practices, and spirituality as predictors of well-being. Research in the Social Scientific Study of Religion, 15, 209-233.

Diener, E., Kesebir, P., \& Tov, W. (2009). Happiness. In M. R. Leary \& R. H. Hoyle (Eds.), Handbook of individual differences in social behavior. New York: Guilford.

Diener, E., Suh, E. M., Lucas, R. E., \& Smith, H. L. (1999). Subjective well-being: Three decades of progress. Psychology Bulletin, 125, 276-302.

Demir, M. (2010). Close relationships and happiness among emerging adults. Journal of Happiness Studies, 11, 293-313.

Demir, M., Orthel, H., \& Andelin, A. K. (2013). Friendship and happiness. In S. David, I. Boniwell \& A. C. Ayers (Eds.), Oxford handbook of happiness. Oxford: Oxford University Press.

Durkheim, E. (1951). Suicide: A study in sociology. New York: Free Press.

Ellison, C. G. (1991). Religious involvement and subjective well-being. Journal of Health \& Social Behavior, 32, 80-99.

Ellison, C. G. (1995). Race, religious involvement and depressive symptomatology in a southeastern U.S. community. Social Science \& Medicine, 40, 1561-1572.

Ellison, C. G., Gay, D. A., \& Glass, T. A. (1989). Does religious commitment contribute to individual life satisfaction? Social Forces, 68, 100-123.

Ellison, C. G., \& George, L. K. (1994). Religious involvement, social ties, and social support in a southeastern community. Journal for the Scientific Study of Religion, 33, 46-61. 
Ellison, C. G., \& Levin, J. S. (1998). The religion-health connection: Evidence, theory, and future directions. Health Education \& Behavior, 25, 700-720.

Ellison, C. G., Boardman, J. D., Williams, D. R., \& Jackson, J. S. (2001). Religious involvement, stress, and mental health: Findings from the 1995 Detroit Area Study. Social Forces, 80, 215-249.

Ferrer-i-Carbonell, A., \& Frijters, P. (2004). How important is methodology for the estimates of the determinants of happiness? Economic Journal, 114, 641-659.

Ferris, A. L. (2002). Religion and the quality of life. Journal of Happiness Studies, 3, 199-215.

Francis, L., Ziebertz, H.-G., \& Lewis, C. (2003). The relationship between religion and happiness among German students. Pastoral Psychology, 51, 273-281.

Frey, B. S., \& Stutzer, A. (2002). What can economists learn from happiness research? Journal of Economic Literature, 40, 402-435.

Frijters, P., Haisken-DeNew, J. P., \& Shields, M. A. (2004). Money does matter! Evidence from increasing real income and life satisfaction in East Germany following reunification. American Economic Review, 94, 730-740.

George, L. K., Ellison, C. G., \& Larson, D. B. (2002). Explaining the relationships between religious involvement and health. Psychological Inquiry, 13, 190-200.

Greeley, A., \& Hout, M. (2006). The truth about convervative Christians. Chicago, IL: University of Chicago Press.

Hadaway, C. K. (1978). Life satisfaction and religion: A reanalysis. Social Forces, 57, 636-643.

Hadaway, C. K., \& Roof, W. C. (1978). Religious commitment and the quality of life in American society. Review of Religious Research, 19, 295-307.

Haslam, A., Jetten, J., Postmes, T., and Haslamm, C. (2009). Social identity, health, and wellbeing: An emerging agenda for Applied Psychology. Applied Psychology: An International Review, 58, 1-23.

Inglehart, R.F. (2010). Faith and freedom: Traditional and modern ways to happiness. In E. Diener, J. F. Helliwell, and D. Kahneman (Eds.), International differences in well-being. New York: Oxford University Press.

Kahneman, D., \& Krueger, A. B. (2006). Developments in the measurement of subjective well-being. Journal of Economic Perspectives, 20, 3-24.

Kaldor, P., Hughes, P., \& Black, A. (2010). Spirit matters: How making sense of life affects wellbeing. Melbourne: Mosaic Press. 
Kaldor, P., Black, A., \& Hughes, P. (2012). How Australian people make sense of life and assess its ultimate significance - and the difference it might make. In M. Miner, M. Dowson \& S. Devenish (Eds.), Beyond well-being: Spirituality and human flourishing. Charlotte, NC: Information Age Publishing, Inc.

Koenig, H. G., McCullough, M. E., \& Larson, D. B. (2001). Handbook of religion and health. New York: Oxford University Press.

Krause, N. (2006). Religious doubt and psychological well-being: A longitudinal investigation. Review of Religious Research, 47, 287-302.

Krause, N. (2008). Aging in the Church: How social relationships affect health. West Conshohocken, PA: Templeton Foundation Press.

Krause, N., \& Ellison, C. G. (2009). The doubting process: A longitudinal study of the precipitants and consequences of religious doubt in older adults. Journal for the Scientific Study of Religion, 48, 293-312.

Krause, N., \& Wulff, K. M. (2005). Church-based social ties, a sense of belonging in a congregation, and physical health status. International Journal for the Psychology of Religion, 15, 73-93.

Lee, G. R., \& Ishii-Kuntz, M. (1987). Social interaction, loneliness, and emotional well-being among the elderly. Research on Aging, 9, 459-482.

Levin, J. S. (2012). Religion and positive well-being among Israeli and diaspora Jews: Findings from the World Values Survey. Mental Health, Religion \& Culture, 15, 709720.

Levin, J. S., \& Taylor, R. J. (1998). Panel analyses of religious involvement and wellbeing in African Americans: Contemporaneous vs. longitudinal effects. Journal for the Scientific Study of Religion, 37, 695-709.

Lewis, C. A. (2002). Church attendance and happiness among Northern Irish undergraduate students: No association. Pastoral Psychology, 50, 191-195.

Lewis, C. A., \& Cruise, S. M. (2006). Religion and happiness: Consensus, contradictions, comments and concerns. Mental Health, Religion \& Culture, 9, 213225.

Lewis, C. A., Lanigan, C., Joseph, S., \& De Fockert, J. (1997). Religiosity and happiness: No evidence for an association among undergraduates. Personality and Individual Differences, 22, 119-121.

Lewis, C. A., Maltby, J., \& Burkinshaw, S. (2000). Religion and happiness: Still no association. Journal of Beliefs \& Values, 21, 233-236.

Lim, C., \& Putnam, R. D. (2010). Religion, social networks, and life satisfaction. American Sociological Review, 75, 914-933. 
Lucas, R. E., Diener, E., \& Suh, E. (1996). Discriminant validity of well-being measures. Journal of Personality and Social Psychology, 71, 616-628.

Lyubomirsky, S., King, L., \& Diener, E. (2005a). The benefits of frequent positive affect: Does happiness lead to success? Psychological Bulletin, 131, 803-855.

Lyubomirsky, S., Sheldon, K. M., \& Schkade, D. (2005b). Pursuing happiness: The architecture of sustainable change. Review of General Psychology, 9, 111-131.

Maselko, J., \& Kubzansky, L. D. (2006). Gender differences in religious practices, spiritual experiences and health: Results from the US General Social Survey. Social Science \& Medicine, 62, 2848-2860.

Pinquart, M., \& Sörensen, S. (2000). Influences of socioeconomic status, social network and competence on subjective well-being in later life: A meta-analysis. Psychological Bulletin, 15, 187-224.

Pollner, M. (1989). Divine relations, social relations, and well-being. Journal of Health and Social Behavior, 30, 92-104.

Requena, F. (1995). Friendship and subjective well-being in Spain: A cross-national comparison with the United States. Social Indicators Research, 35, 271-288.

Sobel, M. E. (1982). Asymptotic confidence intervals for indirect effects in structural equation models. Sociological Methodology, 13(1982), 290-312.

Witter, R. A., Stock, W. A., Okun, M. A., \& Earing, M. J. (1985). Religion and subjective well-being in adulthood: A quantitative synthesis. Review of Religious Research, 26, 332-342.

Wooden, M., \& Watson, N. (2007). The HILDA survey and its contribution to economic and social research (so far). Economic Record, 83, 208-231. 
Table 1: The distribution of life satisfaction in Australia $(n=28,962)$

\begin{tabular}{lrrr}
\hline Life satisfaction & Frequency & Proportion & Cumulative Proportion \\
\hline 0 & 31 & 0.10 & 0.10 \\
1 & 36 & 0.12 & 0.22 \\
2 & 104 & 0.35 & 0.57 \\
3 & 219 & 0.73 & 1.30 \\
4 & 347 & 1.16 & 2.46 \\
5 & 1,152 & 3.84 & 6.30 \\
6 & 1,725 & 5.76 & 12.06 \\
7 & 5,847 & 19.51 & 31.58 \\
8 & 10,458 & 34.90 & 66.48 \\
9 & 6,492 & 21.67 & 88.15 \\
10 & 3,551 & 11.85 & 100.00 \\
& & & \\
\hline Total & & 100.00 & \\
\hline
\end{tabular}


Table 2: Descriptive statistics for the variables used in the analysis $(n=28,962)$

\begin{tabular}{|c|c|c|}
\hline Variables & Description & Mean (SD) \\
\hline \multicolumn{3}{|l|}{ Dependent variable } \\
\hline Life satisfaction & $\begin{array}{l}\text { All things considered, how satisfied are you with your life? }(0= \\
\text { totally dissatisfied; } 10=\text { totally satisfied }) \text {. }\end{array}$ & $7.91(1.44)$ \\
\hline \multicolumn{3}{|l|}{ Religious affiliation } \\
\hline No religion & Reference group. & 0.30 \\
\hline Catholic & 1 = Catholic; 0 = otherwise. & 0.23 \\
\hline Anglican & 1 = Anglican; 0 = otherwise . & 0.20 \\
\hline Other Christian & $1=$ Other Christian; $0=$ otherwise. & 0.23 \\
\hline Non-Christian & 1= Non-Christian; 0 = otherwise. & 0.03 \\
\hline Religious attendance & $\begin{array}{l}\text { How often do you attend religious services? Please do not include } \\
\text { ceremonies like weddings or funerals. }\end{array}$ & $2.65(2.14)$ \\
\hline \multicolumn{3}{|l|}{ Social resources } \\
\hline Friends & $\begin{array}{l}\text { I seem to have a lot of friends ( } 1 \text { = strongly disagree; } 7 \text { = strongly } \\
\text { agree). }\end{array}$ & $4.53(1.63)$ \\
\hline Social contact & $\begin{array}{l}\text { How often do you get together socially with friends/relative not } \\
\text { living with you? }\end{array}$ & $4.54(1.45)$ \\
\hline \multicolumn{3}{|l|}{ Control variables } \\
\hline Age & Age in years. & $45.40(17.05)$ \\
\hline Sex & $1=$ Female; $0=$ Male. & 0.53 \\
\hline Education & $\begin{array}{l}\text { Years of education. Post school qualifications were coded as } \\
\text { follows: certificate = } 12 \text { years; diploma = } 12 \text { years; bachelor degree } \\
=15 \text { years; graduate diploma/certificate = } 16 \text { years; and } \\
\text { masters } / \text { doctorate }=17 \text { years. }\end{array}$ & $12.16(2.21)$ \\
\hline Income/10000 & Financial year gross wages and salary. & $3.07(3.80)$ \\
\hline Married & $1=$ Married; $0=$ Not married. & 0.53 \\
\hline Children & Number of children & $1.75(1.51)$ \\
\hline Unemployed & 1= Unemployed; 0 = Not unemployed. & 0.03 \\
\hline Health status & Self-reported health status ( 1 = poor; 5 = excellent $)$. & $3.37(0.95)$ \\
\hline Trauma & $\begin{array}{l}\text { Number of major negative life events (0-7) in past year (separated; } \\
\text { major illness; major illness family member; death of spouse/child; } \\
\text { death of family member; death of close friend; victim of physical } \\
\text { violence; victim of property crime; detention in jail; detention of } \\
\text { family member in jail; major worsening of finances). }\end{array}$ & $0.63(0.89)$ \\
\hline
\end{tabular}


Table 3: OLS regressions of religion on life satisfaction $(n=28,962)$

\begin{tabular}{|c|c|c|c|c|}
\hline & (I) & (II) & (III) & (IV) \\
\hline \multicolumn{5}{|c|}{ Religious affiliation } \\
\hline Catholic & $0.105 * *(0.029)$ & $0.043(0.026)$ & $-0.017(0.028)$ & $-0.026(0.027)$ \\
\hline Anglican & $0.214 * *(0.030)$ & $0.080 * *(0.027)$ & $0.051(0.028)$ & $0.040(0.027)$ \\
\hline Other Christian & $0.160 * *(0.029)$ & $0.041(0.026)$ & $-0.030(0.029)$ & $-0.037(0.029)$ \\
\hline Non-Christian & $-0.045(0.059)$ & $-0.088(0.054)$ & $-0.153 * *(0.055)$ & $-0.156 * *(0.053)$ \\
\hline \multicolumn{5}{|c|}{ Control variables } \\
\hline Age & & $0.013^{* *}(0.001)$ & $0.013^{* *}(0.001)$ & $0.013^{* *}(0.001)$ \\
\hline Sex & & $0.088 * *(0.020)$ & $0.083^{* *}(0.020)$ & $0.044 *(0.020)$ \\
\hline Education & & $-0.056 * *(0.005)$ & $-0.059 * *(0.005)$ & $-0.056 * *(0.005)$ \\
\hline Income & & $-0.010 * *(0.002)$ & $-0.009 * *(0.002)$ & $-0.006 *(0.002)$ \\
\hline Married & & $0.255 * *(0.022)$ & $0.250 * *(0.022)$ & $0.287 * *(0.021)$ \\
\hline Children & & $-0.025 * *(0.008)$ & $-0.028 * *(0.008)$ & $-0.022 * *(0.008)$ \\
\hline Health & & $0.547 * *(0.012)$ & $0.544 * *(0.012)$ & $0.481^{* *}(0.012)$ \\
\hline Unemployed & & $-0.315 * *(0.065)$ & $-0.311^{* *}(0.065)$ & $-0.260 * *(0.063)$ \\
\hline Trauma & & $-0.112 * *(0.011)$ & $-0.112 * *(0.011)$ & $-0.119 * *(0.011)$ \\
\hline Attendance & & & $0.028 * *(0.005)$ & $0.013^{* *}(0.005)$ \\
\hline \multicolumn{5}{|l|}{ Social resources } \\
\hline Friends & & & & $0.154^{* *}(0.006)$ \\
\hline Social contact & & & & $0.067 * *(0.007)$ \\
\hline Constant & $7.804 * *(0.019)$ & $6.064 * *(0.081)$ & $6.091 * *(0.082)$ & $5.298 * *(0.087)$ \\
\hline$R^{2}$ & 0.003 & 0.154 & 0.155 & 0.195 \\
\hline
\end{tabular}


Table 4: Panel regressions of religion on life satisfaction $(n=17,676)$

\begin{tabular}{|c|c|c|c|c|}
\hline & (I) -- FE & (II) -- FE & (III) -- RE & (IV) -- RE \\
\hline \multicolumn{5}{|l|}{ Religious affiliation } \\
\hline Catholic & $0.068(0.088)$ & $0.046(0.086)$ & $0.000(0.038)$ & $-0.009(0.035)$ \\
\hline Anglican & $0.106(0.056)$ & $0.079(0.057)$ & $0.156 * *(0.034)$ & $0.083 * *(0.032)$ \\
\hline Other Christian & $0.063(0.050)$ & $0.056(0.049)$ & $0.056(0.035)$ & $0.007(0.033)$ \\
\hline Non-Christian & $0.138(0.156)$ & $0.155(0.146)$ & $-0.086(0.079)$ & $-0.080(0.072)$ \\
\hline Attendance & $0.034 *(0.014)$ & $0.032 *(0.013)$ & $0.026 * *(0.007)$ & $0.014 *(0.006)$ \\
\hline \multicolumn{5}{|l|}{ Social resources } \\
\hline Friends & $0.072 * *(0.010)$ & $0.066 * *(0.010)$ & $0.149 * *(0.008)$ & $0.128 * *(0.008)$ \\
\hline Social contact & $0.036 * *(0.010)$ & $0.028 * *(0.010)$ & $0.050 * *(0.009)$ & $0.053 * *(0.008)$ \\
\hline Constant & $7.290 * *(0.076)$ & $6.890 * *(0.309)$ & $6.916^{* *}(0.053)$ & $5.490 * *(0.113)$ \\
\hline Additional controls & No & Yes & No & Yes \\
\hline$R^{2}$ & 0.010 & 0.042 & -- & -- \\
\hline
\end{tabular}

Standard errors in parentheses. ${ }^{*} p<0.05,{ }^{* *} p<0.01$. Additional controls comprise: age in years, sex (for RE models only), years of education, income, marital status, number of children, self-reported health status, unemployment status, and the number of major negative life events in the previous 12 months. 